Article

\title{
Site Fidelity, Habitat Use, and Movement Patterns of the Common Carp during Its Breeding Season in the Pearl River as Determined by Acoustic Telemetry
}

\author{
Yingqiu Zhang ${ }^{1}$, Yuefei $\mathrm{Li}^{1}$, Lili Zhang ${ }^{2}$, Zhi Wu ${ }^{1}$, Shuli Zhu ${ }^{1}$, Jie Li ${ }^{1}$ and Xinhui $\mathrm{Li}^{1}{ }^{1, *(1)}$ \\ 1 Pearl River Fisheries Research Institute, Chinese Academy of Fishery Sciences, No. 1 Xingyu Rd., \\ Liwan District, Guangzhou 510380, China; zyq@prfri.ac.cn (Y.Z.); lyf@prfri.ac.cn (Y.L.); \\ wz@prfri.ac.cn (Z.W.); zhshl@prfri.ac.cn (S.Z.); lijie1561@prfri.ac.cn (J.L.) \\ 2 Institute of Geochemical Exploration and Marine Geological Survey, East China Mineral Exploration and \\ Development Bureau for Non-ferrous Metals, Nanjing 210000, China; 15266204291@163.com \\ * Correspondence: lixh@prfri.ac.cn; Tel.: +86-20-81611961
}

Received: 17 June 2020; Accepted: 6 August 2020; Published: 8 August 2020

\begin{abstract}
Understanding fish migration patterns and habitat use is essential for fisheries management. We conducted an acoustic fine-scale tracking experiment from March to June 2017 to determine the common carp movement pattern and habitat use in the downstream area of the Pearl River. The eight tagged common carp were detected for $39.38 \pm 29.57 \mathrm{~d}$, on average, with a total average detection period of $42.12 \pm 28.02 \mathrm{~d}$. A general linear mixed model suggested they were detected more during the night than during the day. Common carp preferred habitats near the sandbar and riparian shallow habitats, as revealed by their movement tracks and habitat selection indexes. The general additive mixed model (GAMM) analysis of their shortest distances to riverbanks and depth indicated that they migrated to shallower riparian habitat more frequently during the night than during the day. The continuous wavelet spectrum further confirmed the significant diel pattern of their vertical movement. Their habitat use was also influenced by the water temperature, water level, and river discharge, as suggested by the GAMM. Our results provide novel information on common carp spatiotemporal movement and habitat use patterns, and have important implications for its native population restoration and the invasive population control/exclusion.
\end{abstract}

Keywords: Cyprinus carpio; diel movement rhythm; habitat use; movement behaviors

\section{Introduction}

Studies on fish movement and/or migration behavior have been widely carried out in marine [1,2] and freshwater [3,4] environments. Animal movement is defined by a change in its geographic location. The decision to move is a response to the environmental conditions experienced by animals. Animals' selective movements yield their habitat use [5]. To reduce the frequency of leaving a suitable habitat, animals increase their residence time by decreasing the speed and increasing the tortuosity of their movements. To increase the frequency of visiting suitable areas, individuals direct their movement towards these areas [6]. The relationship between environmental characteristics and space-use patterns is the result of their direct effects on animal movement, i.e., the environment affects an animal's movements, and these movements, in turn, determine the space use of the environment [6]. Thus, fish movement data provide knowledge of space-use patterns in geographic and/or environmental spaces and link home ranges and habitat selection [6].

Moreover, ontogenetic shifts in habitat use by fishes at multiple scales of the river ecosystem are a characteristic evolutionary phenomenon $[7,8]$. The fish movements through different life-history stages, especially the key stage of spawning periods, to suitable habitat patches are essential to maintain 
stable population dynamics [8]. Variation in the abundance at temporal and spatial scales is the result of ontogenetic shifts or diel changes in vertical and horizontal movements [9]. Such movements are strongly related to reproduction, feeding or predator avoidance behavior [10,11]. Diel and seasonal variation in the composition, abundance and distribution of fish in many lowland river systems can have significant implications for the degree of top-down trophic regulation and food web structure and dynamics [12]. Hence, knowledge of the temporal and spatial movement and habitat use of the target fish species during its key life-history stages is critical for fish population/community management, river ecosystem conservation, and river health improvement.

Regarding fish movement detection approaches, the past six decades have witnessed the emergence and great development of acoustic and satellite tracking technologies to remotely study the behaviors of multiple fish species [13]. Acoustic telemetry has been widely used for studying fish movement patterns on spatial and temporal scales in freshwater areas. Environmental effects, including habitat structure and contamination, on fish movements have also been studied in this way [14]. In this study, we use acoustic telemetry to analyze the spatiotemporal movement and habitat use characteristics of the common carp, Cyprinus carpio, during its spawning season in the West River, which is the trunk stream of the Pearl River, the largest river in southern China.

The common carp is a freshwater fish species belonging to the Cyprinidae. It was originally distributed in Eurasia and has now been introduced all over the world due to its importance in aquaculture and recreational fisheries [15,16], but has had devastating impacts on aquatic ecosystems through stirring up the sediments, uprooting aquatic plants, and degrading water quality in Africa, America, and Oceania [17]. As a common species in Chinese rivers, lakes, and reservoirs, it tends to swim in groups in middle and bottom waters at a slow velocity [15]. Common carp are omnivorous and feed on small and demersal invertebrates. During the spawning season, from January to June [18], and particularly from early February to late April, when the water temperatures range from 16 to $22{ }^{\circ} \mathrm{C}$ in the Zhaoqing section of the West River [19], sexually mature females usually aggregate and spawn. Due to pressures from river regulations related to channelization and dams, wild common carp populations, e.g., the native common carp in Europe, have been declining [20]. The situation of the wild common carp population in the Pearl River is also serious. Since the Changzhou hydrojunction started to dam the Pearl River in 2004, the downstream common carp population has decreased to a greater extent than the midstream and upstream populations. To recover the common carp population in the downstream Pearl River area, artificial fish nests (AFNs) and relevant stock enhancement measures have been used in experiments in the Zhaoqing section (Guangdong Province) since 2004. AFNs are structures that float on the water surface; the sticky eggs produced by common carp, goldfish, etc., adhere to these structures and hatch. AFNs are made by bundling together pieces of the giant reed, Arundo donax, or other natural/artificial materials and then connecting these bundles with bamboo and rope (Figure S1). The proposition of stock enhancement through constructing artificial reefs (fish nests) in the Chinese Program of Actions for the Conservation of Aquatic Biological Resources announced in 2014 facilitated AFN demonstration and popularization. From 2014 to 2016, AFNs were constructed all over Guangdong Province. The AFNs in this province had a yearly area of 34,000 to $40,000 \mathrm{~m}^{2}$ and 430 to 630 million adhered eggs, which showed their evident ecological benefits [21].

Despite the large number of eggs adhering to AFNs, the function of AFN in providing spawning habitats for common carp adults during breeding seasons is still unclear. Knowledge of the common carp adult distribution, migration pattern, and habitat use in the Pearl River does not support the ecological benefits of AFNs. Thus, from March to June 2017, we conducted an acoustic telemetry study in the downstream Pearl River area to explore the spatiotemporal movement behaviors and habitat use patterns of common carp adults during the spawning season. Our study aimed to provide new data on (i) site fidelity and spatiotemporal movements in the acoustic array; (ii) the pattern of habitat use on natural habitats and artificial habitats and (iii) the vertical movement behaviors of this species during the breeding season. Because of the status of common carp in the Pearl River, and its extensive 
invasion around the world, our study might provide some useful information not only on its native population management, but also to control the invasive population.

\section{Materials and Methods}

Common carp collection and tagging and the deployment of the receiver mooring system in the West River were both permitted by the Zhaoqing team of the Guangdong Province Fishery Administration. All the procedures were performed under the regulations for the Administration of Affairs Concerning Experimental Animals of China (2011.1) and the regulations for the Administration of Affairs Concerning Experimental Animals of Guandong Province (2010.6). The study was approved by the ethics committee of the Pearl River Fisheries Research Institute, CAFS. Our study did not involve endangered or protected species, and no animals were sacrificed. Acoustic tags were attached to fish after anesthetization with MS-222, and all efforts were made to minimize fish handling and harm.

\subsection{Study Area}

Common carp acoustic tracking was performed downstream of the West River (Figure 1), the trunk stream of the Pearl River in southern China. Our study area covered the depth from $0 \mathrm{~m}$ (riverbanks) to $38 \mathrm{~m}$ (Figure 1), including the mixed habitat of aquatic plants and the muddy bottom. The water level (the height of the water surface at the designed site of the West River over the Pearl River height datum of China), water depth and water velocity fluctuations in this area are mainly influenced by seasonal rainfall and the Changzhou Dam regulation in the upper stream area. On 8 March 2017, local authorities deployed $5 \mathrm{~m} \times 250 \mathrm{~m}$ AFNs made of giant reed and bamboo (Figure S1) in the study area and these AFNs were floating on the water surface and anchored by bamboo poles until 1 May 2017, when the local authorities removed them. 


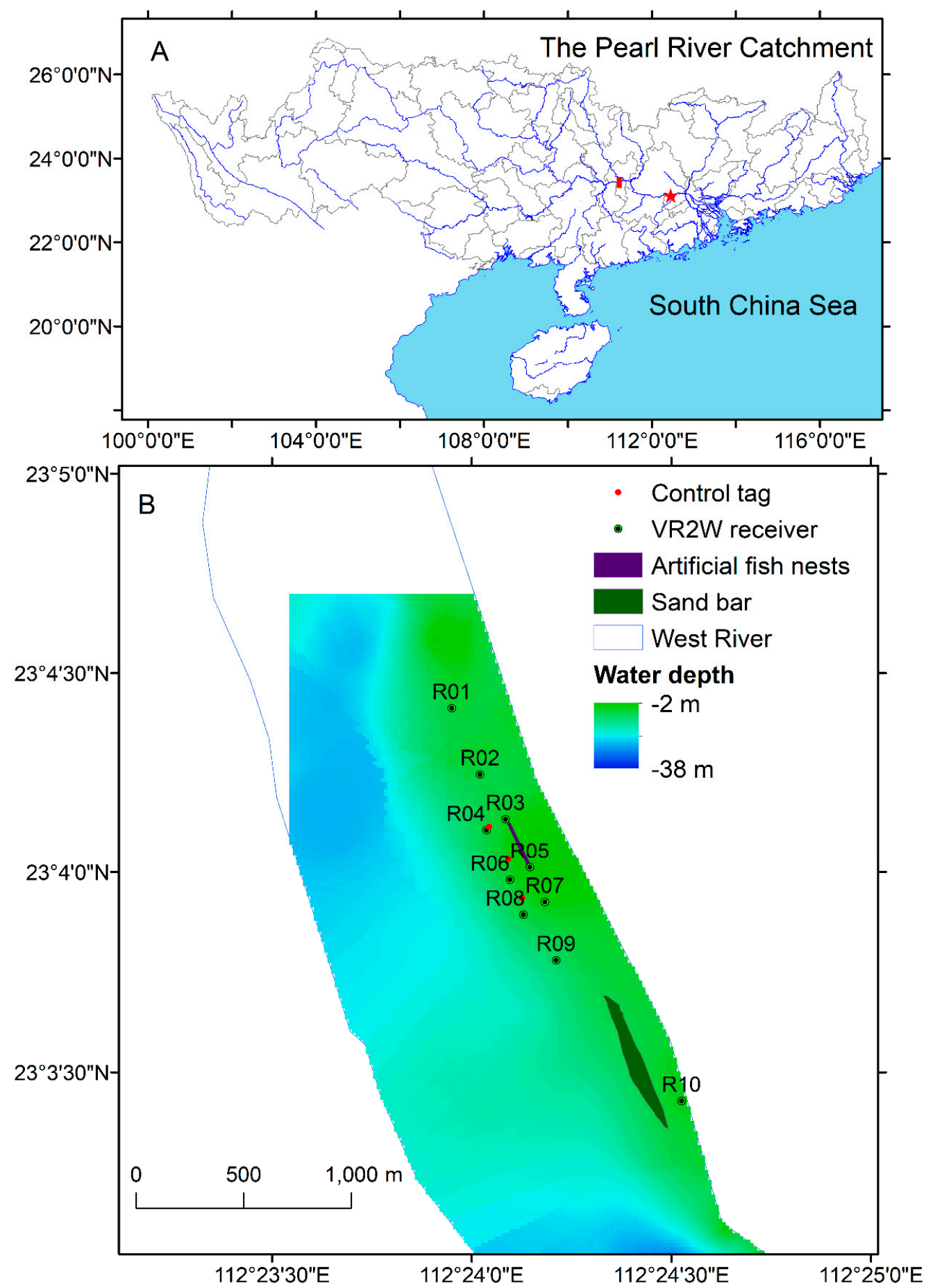

Figure 1. The study area was located in the downstream region of the Pearl River, shown by the red star, and the Changzhou hydrojunction (the red elongated rectangular mark) was located in the midstream (A); The locations of control tags, VR2W receivers, and habitats including artificial fish nests and the sand bar, and water depth in the study area are shown in (B).

\subsection{Receiver Placement}

On 21 March 2017, 10 acoustic receivers (model VR2W, VEMCO, Bedford, NS, Canada) were deployed on the river bottom using anchors. The detection range of the VR2W receiver was obtained by a detection range test lasting for an hour. The range test tag (model: A69-1601-22557, $10 \mathrm{~s}$ burst interval) and six VR2W receivers were fixed $5 \mathrm{~m}$ deep in separate positions. As the range test suggested 
that more than half of the detections occurred at a distance of approximately $250 \mathrm{~m}$ (Figure S2), we fixed the VR2W receivers at a distance less than $250 \mathrm{~m}$ between each other, ranging from $100 \mathrm{~m}$ to $250 \mathrm{~m}$. As acoustic tag detection is easily influenced by environmental factors, three control tags (V9-1H-A69-1601; diameter, $9 \mathrm{~mm}$; length, $24 \mathrm{~mm}$; weight in the air, $3.6 \mathrm{~g}$; weight in the water, $2.2 \mathrm{~g}$; power output, $151 \mathrm{~dB}$ re $1 \mu \mathrm{Pa}$ at $1 \mathrm{~m}$; lifespan, $455 \mathrm{~d}$; burst interval, 500 to $700 \mathrm{~s}$ ) were anchored separately in the receiver array (Figure 1B).

\subsection{Tag Attachment}

In March 2017, nine individuals of common carp, with standard lengths ranging from $250 \mathrm{~mm}$ to $440 \mathrm{~mm}$ (Table 1), were successively caught in the study area without precise locations using conventional cage nets. The sex of the sampled common carp individuals was determined through their belly appearance and genital aperture characters. Usually the female ones have broader and rounder belly, and large, reddish, and thick-lip genital aperture, while the male ones have flat belly and narrow genital aperture. These individuals were held for several days in floating cages. Each individual was anesthetized using a dose of $100 \mathrm{mg} / \mathrm{L} \mathrm{MS-222} \mathrm{before} \mathrm{tag} \mathrm{attachment.} \mathrm{On} 19$ March, four individuals were tagged with acoustic transmitters (model: V9-1H-A69-1601; diameter, 9 mm; length, 24 mm; weight in the air, $3.6 \mathrm{~g}$; weight in the water, $2.2 \mathrm{~g}$; power output, $151 \mathrm{~dB}$ re $1 \mu \mathrm{Pa}$ at $1 \mathrm{~m}$ ). On $22 \mathrm{March}$, three individuals were tagged with acoustic transmitters (model: V9-1H-A69-1601). On 28 March, two more individuals were tagged with acoustic pressure transmitters (model: V9-2H-A69-9006; diameter, $9 \mathrm{~mm}$; length, $29 \mathrm{~mm}$; weight in the air, $4.7 \mathrm{~g}$; weight in the water, $2.9 \mathrm{~g}$; power output, $151 \mathrm{~dB}$ re $1 \mu \mathrm{Pa}$ at $1 \mathrm{~m}$ ). The nine common carp were tagged using an external attachment. This method is quick, easy to perform, and causes minimal injuries to the bodies of the fish. The fish tag was first bound in rings using nylon thread and then attached to the single coarse dorsal spine of the common carp (Figure S3). The tagging process lasted approximately $2 \mathrm{~min}$ for each fish. After being held in the floating cages for more than $24 \mathrm{~h}$, the fish were released in the study area. After 3 months of the receiver recording the tagged fish underwater, we recovered the receiver and downloaded the data. Based upon the acoustic data, we derived the geographic positions of the tagged common carp from the Vemco positioning system (VPS).

Table 1. Information on fish tags, the biological characteristics of the tagged common carp individuals, including sex, standard length (SL), and total length (TL), fish tag attachment time, and tagged fish release time.

\begin{tabular}{cccccccc}
\hline ID & $\begin{array}{c}\text { Tag Life } \\
(\mathbf{d})\end{array}$ & $\begin{array}{c}\text { Burst } \\
\text { Interval } \\
(\mathbf{s})\end{array}$ & Sex & $\begin{array}{c}\text { SL } \\
(\mathbf{m m})\end{array}$ & TL (mm) & $\begin{array}{c}\text { Tag Attaching } \\
\text { Time }\end{array}$ & Releasing Time \\
\hline 46912 & 188 & $60-180$ & undetermined & 390 & 500 & 19 March 2017 14:00 & 21 March 2017 14:00 \\
46913 & 188 & $60-180$ & Female & 340 & 440 & 19 March 2017 14:00 21 March 2017 14:00 \\
46914 & 188 & $60-180$ & undetermined & 345 & 440 & 19 March 2017 14:00 21 March 2017 14:00 \\
46916 & 188 & $60-180$ & Female & 305 & 370 & 19 March 2017 14:00 21 March 2017 14:00 \\
46694 & 124 & $45-105$ & Male & 250 & 290 & 22 March 2017 14:00 29 March 2017 11:00 \\
46696 & 124 & $45-105$ & Male & 400 & 450 & 22 March 2017 14:00 29 March 2017 11:00 \\
46697 & 124 & $45-105$ & Female & 350 & 420 & 22 March 2017 14:00 29 March 2017 11:00 \\
217 & 251 & $60-180$ & Male & 350 & 420 & 28 March 2017 11:00 29 March 2017 11:00 \\
218 & 251 & $60-180$ & Female & 440 & 530 & 28 March 2017 11:00 29 March 2017 11:00 \\
\hline
\end{tabular}

\subsection{Data Analysis}

The detection data were filtered to remove spurious detections, defined as any single transmitter code in a $24 \mathrm{~h}$ period. A fish continuously and steadily detected by only one receiver was recognized as being trapped or dead. In this study, fish ID 46912 was removed from the data analysis. The residence time was estimated as residence days (RDs, d), the total number of days detected in the study area. The residence index (RI) was calculated as RDs divided by the total period (TP, d) from the day each fish was released to the last detection of the individual fish. 
The effect of the diel phase (DN, day vs. night) on hourly detections of control tags and tagged fish was tested by fitting a generalized linear mixed model (GLMM) using the glmmTMB package in R [22]. During the experimental period, from March to June, the sun rose at approximately 06:00 and set at approximately 19:00 in Zhaoqing, and these times were used to define the diel phase. In the GLMM, the diel phase was considered an independent variable and treated as a fixed factor, while tag ID was treated as an independent random factor. The GLMMs were computed using Poisson distribution, but suffered over dispersion with the dispersion values $>1$ (Poisson distribution requires dispersion to be 1 [23]). Then the zero-inflated GLMMs were computed using Poisson, Gaussian, and negative binomial distributions. The zero-inflated GLMMs with negative binomial distributions resulted in the lowest Akaike information criterion (AIC) values; therefore, these models were selected to analyze the effects of the diel phase on hourly detections [24].

We assessed the preference for or avoidance of each fish to the habitat around each receiver by calculating the habitat selection index (HSI). HSI is the ratio of the detection percentage at each receiver to the proportion of the detection range of each receiver, which equals 1/10. Preference for or avoidance of the habitat around each receiver was estimated as the degree of deviation from a value of 1 , in which HSI $>1$ indicates preference, while HSI $<1$ indicates avoidance.

The precise geographic positions of the common carp were calculated through the VPS technology based on acoustic detections. We further calculated the shortest distance to the riverbanks (SDR) using the dist2Line function of the geosphere package in $\mathrm{R}$ at each position and the moving speed for each tagged fish. The fish depth data were collected for the two individuals with acoustic pressure transmitters (IDs 217 and 218). We assessed the temporal variations in common carp behaviors through a continuous wavelet transform (CWT) to identify the periodicity pattern in vertical depth at time scales of 2, 4, 8, 16, 24, 32, and $64 \mathrm{~h}$. The library WaveletComp in R was used to compute the two-dimensional wavelet spectrum; a 95\% significance level was used during the CWT process [25]. Furthermore, to analyze the environmental effects on the SDRs, moving speed and depth, we tested the collinearity between the explanatory environmental variables, including water temperature, water level, and river discharge. These three environmental variables were strongly correlated, with correlation magnitudes greater than \pm 0.05 [26]. Then, we analyzed the effects of diel phase (hour) and each environmental variable through the generalized additive mixed model (GAMM), which was implemented by the gamm function of the mgco package in $\mathrm{R}$.

\section{Results}

From 21 March to $17 \mathrm{June}$ in 2017 , the water temperature in the study area was $22.86^{\circ} \mathrm{C} \pm 3.24{ }^{\circ} \mathrm{C}$ (mean \pm s.d.), ranging from $17.50^{\circ} \mathrm{C}$ to $27.58^{\circ} \mathrm{C}$, the water level was $1.07 \pm 0.53 \mathrm{~m}$, ranging from $0.20 \mathrm{~m}$ to $2.38 \mathrm{~m}$, and the river discharge was $7798 \pm 1952 \mathrm{~m}^{3} / \mathrm{s}$, ranging from 4190 to $12,600 \mathrm{~m}^{3} / \mathrm{s}$ (Figure S4).

\subsection{Site Fidelity and Diel Detection Pattern}

A total of 121,799 acoustic detections were collected for the eight tagged fish in our acoustic tracking experiment over the $89 \mathrm{~d}$ tracking period in the West River (Figure 2). The mean $( \pm$ s.d.) number of detections of each fish was 15,225 $\pm 12,068$ and ranged from 1189 (ID: 217) to 30,403 (ID: 46914). The fish were detected by at least six receivers (ID: 46914) and a maximum of 10 receivers (IDs: 218, 46696, 46697, 46913, and 46916), with an average of $9.1 \pm 1.5$ receivers. 


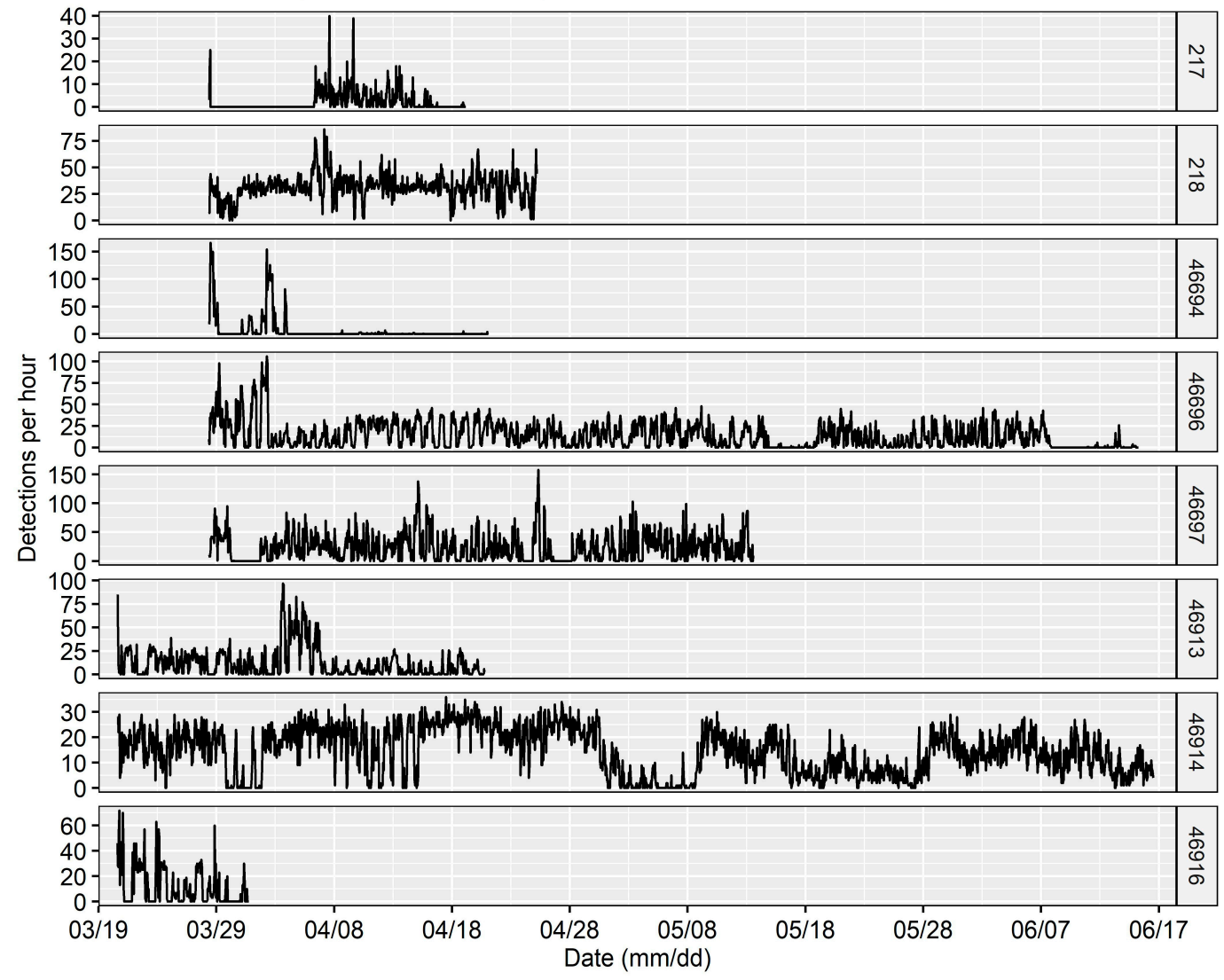

Figure 2. Hourly detection of each tagged fish during the study period from March to June 2017.

The RDs of the tagged fish ranged from 12 to $89 \mathrm{~d}$, with an average of $39.38 \pm 29.57 \mathrm{~d}$ ( \pm s.d.). The TP was an average of $42.12 \pm 28.02 \mathrm{~d}$, ranging from 12 to $89 \mathrm{~d}$. Fish 46914 was detected throughout the whole study period, for a total of $89 \mathrm{~d}$. However, two fish (IDs: 217 and 46916) were detected for only 14 and $12 \mathrm{~d}$, respectively. The other five common carp were detected for RDs ranging from 18 to $45 \mathrm{~d}$ (Table 2). The RI of the tagged common carp in the study area ranged from 0.61 to 1 , with an average value of $0.91 \pm 0.15$ (Table 2).

Table 2. Residence days (RD), the total period (TP) being detected and the residence index of the tagged common carp individuals in the Zhaoqing section of the West River.

\begin{tabular}{cccc}
\hline ID & RD (d) & TP (d) & Residence Index \\
\hline 217 & 14 & 23 & 0.61 \\
218 & 29 & 29 & 1 \\
46694 & 18 & 25 & 0.72 \\
46696 & 78 & 80 & 0.98 \\
46697 & 45 & 47 & 0.96 \\
46913 & 32 & 32 & 1 \\
46914 & 89 & 89 & 1 \\
46916 & 12 & 12 & 1 \\
\hline
\end{tabular}

The average hourly binned detections plot indicated a daily pattern of more detections during the night $\left(20.65 \pm 16.54 \mathrm{~h}^{-1}\right)$ than during the day $\left(19.44 \pm 17.24 \mathrm{~h}^{-1}\right)$, for the tagged common carp. In contrast, the mean hourly detections for the control tags revealed a higher number of detections during the day $\left(17.21 \pm 7.11 \mathrm{~h}^{-1}\right)$ than during the night $\left(15.94 \pm 6.87 \mathrm{~h}^{-1}\right)$ (Figure 3). The GLMM fitted to the common carp detections confirmed the significant effects of the diel phase on the hourly fish tag detections (Table 3). In addition, the GLMM fitted to the control tag detections did not show 
significant changes between day and night, which excluded environmental causes of the diel pattern of fish tag detections.

$\rightarrow$ control tag detections $\rightarrow$ fish tag detections

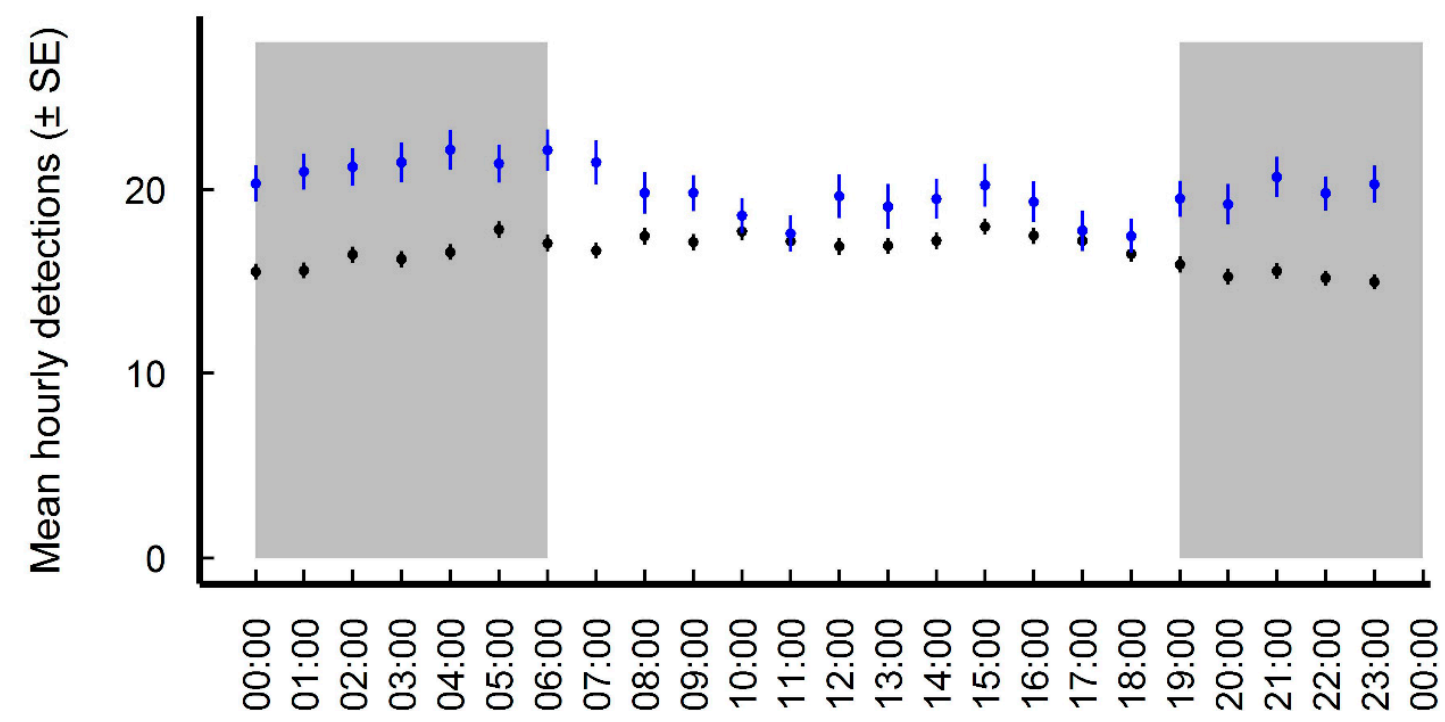

Hour (hh:mm)

Figure 3. The diel pattern of mean hourly detections ( \pm se) of the tagged fish and control tags.

Table 3. GLMM analysis of the effects of diel phase on hourly detections of fish tags and control tags.

\begin{tabular}{ccccc}
\hline & Estimate & Std. Error & z Value & Pr $(>|\mathbf{z}|)$ \\
\hline \multicolumn{4}{c}{ diel phase effects } & on hourly fish tag detections \\
\hline (Intercept) & 2.844 & 0.133 & 21.41 & $<2.0 \times 10^{-16}$ \\
Day vs. night & 0.111 & 0.0234 & 4.744 & $2.1 \times 10^{-6}$ \\
\hline \multicolumn{5}{c}{ No significant diel pattern for hourly control tag detections } \\
\hline (Intercept) & 2.747 & 0.118 & 23.191 & $<2.0 \times 10^{-16}$ \\
Day vs. night & 0.0132 & 0.00879 & 1.504 & 0.133 \\
\hline
\end{tabular}

\subsection{Habitat Use}

The detections at each receiver and the movement tracks in Figure 4 show the spatial distribution of the tagged common carp (Figure 4). The individual HSI (as shown in Table 4) shows the preference for or avoidance of the habitat around each receiver. The mean HSI of all the individuals indicates that common carp preferred the habitat near receivers R10 and R01, in decreasing order (mean HSI > 1), avoided the habitats around receivers R09, R06, R05, R08, R04, and R07 (mean HSI < 1), and neither preferred nor avoided the habitat around receivers R02 and R03 (mean HSI approximately 1). Moreover, common carp habitat preferences vary greatly among individuals. Fish 46696, 46913, and 46916 showed strong preferences for habitat around receiver R10, as each of them had an HSI > 4.5. The habitat around receiver R10 was near the sand bar downstream of the study area and was characterized by slow velocity and abundant aquatic plants. Fish 217 and fish 46914 preferred the habitat around receiver R01, upstream of the study area. The mean HSI suggested that common carp did not prefer the AFNs located between receivers R03 and R05, but the individual HSI values revealed that fish 217, 46694, and 46697 preferred the habitat around receivers R03 or R05. 


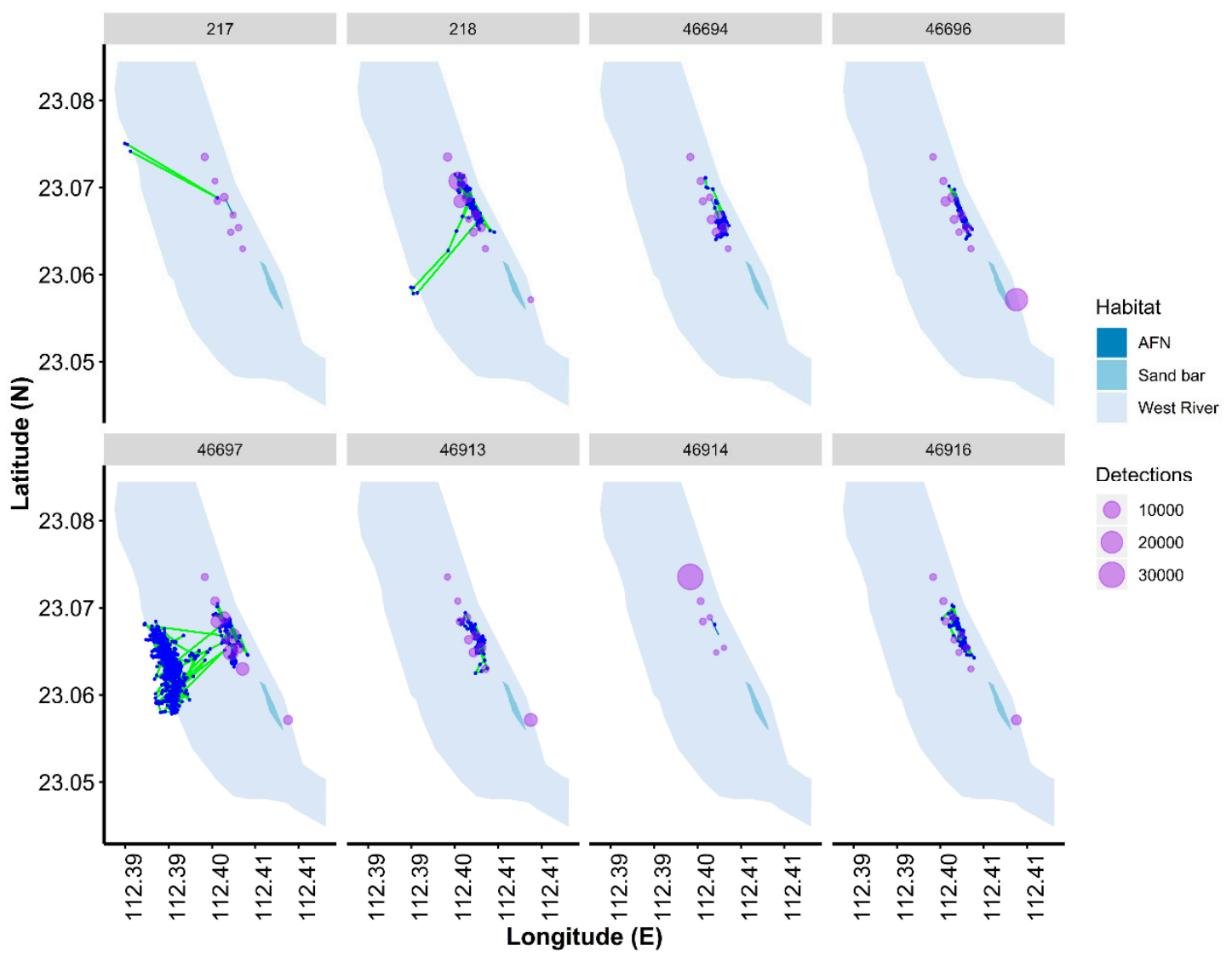

Figure 4. Spatial detection pattern and the calculated track routes for each fish in the West River with artificial fish nests (AFNs) and sand bar habitats.

Table 4. Individual fish habitat selection index (HSI) for the habitats around each receiver.

\begin{tabular}{ccccccccccc}
\hline \multirow{2}{*}{ Fish ID } & \multicolumn{10}{c}{ HSI Around Each Receiver } \\
\cline { 2 - 11 } & R01 & R02 & R03 & R04 & R05 & R06 & R07 & R08 & R09 & R10 \\
\hline 217 & $\mathbf{2 . 7 4}$ & 0.13 & $\mathbf{4 . 1 9}$ & 0.81 & 0.60 & 0.00 & 0.93 & 0.51 & 0.10 & 0.00 \\
218 & 0.34 & $\mathbf{5 . 7 6}$ & 0.92 & $\mathbf{1 . 8 9}$ & 0.49 & 0.01 & 0.35 & 0.21 & 0.03 & 0.01 \\
46694 & 0.58 & 0.63 & 0.29 & 0.61 & $\mathbf{1 . 7 0}$ & $\mathbf{1 . 9 1}$ & $\mathbf{2 . 4 7}$ & $\mathbf{1 . 7 5}$ & 0.06 & 0.00 \\
46696 & 0.05 & 0.10 & 0.50 & 0.47 & 0.19 & 0.19 & 0.39 & 0.04 & 0.02 & $\mathbf{8 . 0 5}$ \\
46697 & 0.09 & 0.30 & 1.00 & $\mathbf{1 . 5 5}$ & $\mathbf{1 . 6 4}$ & 0.03 & 0.86 & $\mathbf{2 . 6 0}$ & $\mathbf{1 . 5 5}$ & 0.36 \\
46913 & 0.05 & 0.08 & 0.41 & 0.41 & 0.86 & 0.81 & $\mathbf{1 . 4 2}$ & 0.98 & 0.42 & $\mathbf{4 . 5 7}$ \\
46914 & $\mathbf{9 . 8 8}$ & 0.06 & 0.00 & 0.05 & 0.00 & 0.00 & 0.00 & 0.00 & 0.00 & 0.00 \\
46916 & 0.61 & 0.94 & 0.79 & 0.91 & 0.39 & 0.43 & 0.62 & 0.24 & 0.16 & $\mathbf{4 . 9 0}$ \\
Mean & $\mathbf{1 . 7 9}$ & 1.00 & $\mathbf{1 . 0 1}$ & 0.84 & 0.73 & 0.42 & 0.88 & 0.79 & 0.29 & $\mathbf{2 . 2 4}$ \\
\hline
\end{tabular}

Note: the values $>1$ were in bold, and indicate the habitat preference.

\subsection{Diel Movement Behaviors and Environmental Effects}

In total, 2934 positions were obtained for the 8 individuals during the 55-d period from 21 March to 14 May. The movement tracks indicate that common carp prefer riparian habitats (Figure 4). The SDR data further show that common carp tend to stay near riverbanks during the night but move farther away from riverbanks during the day (Figure 5A). In addition, the SDR showed oscillating relationships with the water temperature, the water level, and the river discharge, as shown in Figure 5B-D. The GAMM confirmed the effects of the diel phase, as well as the effects of the water temperature, water level, and river discharge on the SDR (Table 5). Model S3 was the best model 
according to the AIC and $\mathrm{R}^{2}$ adj values, but the likelihood ratio test (LRT) suggested no significant differences in model performance among S2, S3, and S4 (Table 5).
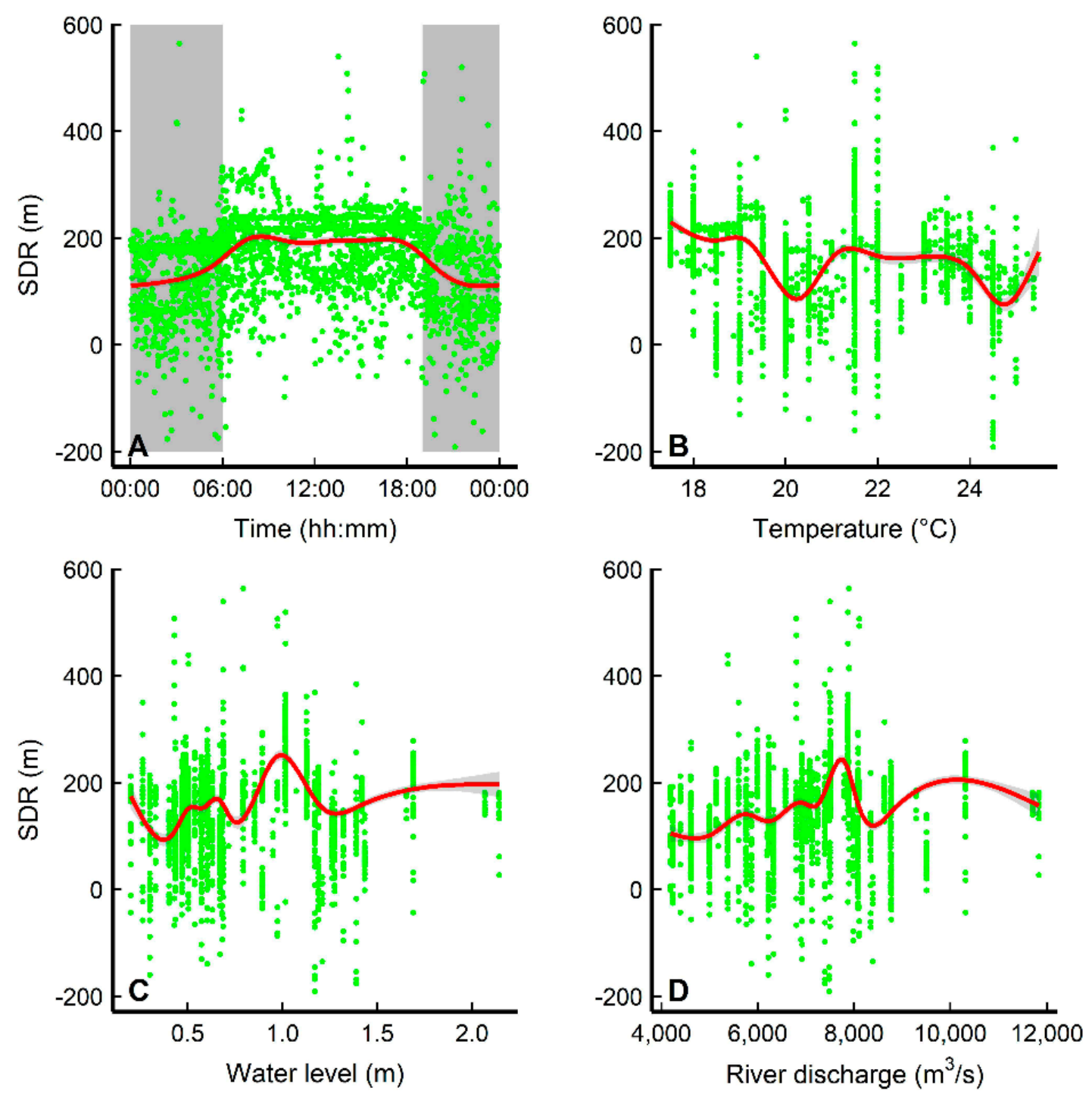

Figure 5. Effects of diel phase, temperature, water level, and river discharge on the shortest distance to riverbanks (SDR) of common carp. A smoothing (gam) curve with a span width of 0.5 was added for visual interpretation.

However, moving speed exhibits no difference between day and night, as suggested by the GAMM. The fitted model with the largest AIC and $\mathrm{R}^{2}$ adj values, in which the smoothing hour and smoothing water level were treated as explanatory variables, explained only $2.87 \%$ of the variance in the moving speed.

Fish depth data were collected during the periods from 29 March to 26 April for common carp IDs 217 and 218, for which 1192 and 20,903 observations were collected during 15 days and 29 days, respectively. The depth data indicate an evident diel vertical pattern of shifting from the deep water during the day to the shallow water during the night, i.e., common carp tended to move to shallow water or water surfaces during the night and dawn but migrated to deep water during the day (Figure 6 and Table 5). The GAMM showed the significant effects of hour and environmental factors, including water temperature, water level, and river discharge. In accordance with models on the SDR, D3 was the best model based on the AIC values, but the LRT suggested no significant differences 
among D2, D3 and D4 (Table 5). The CWT further confirmed the diel periodicity (24 h) in its vertical movement for most of the tracking periods. Diel periodicity was evident for fish 217 during the period of 9-20 April and fish 218 during periods of 29 March-2 April, 4-15 April, and 21-26 April (Figure 7).
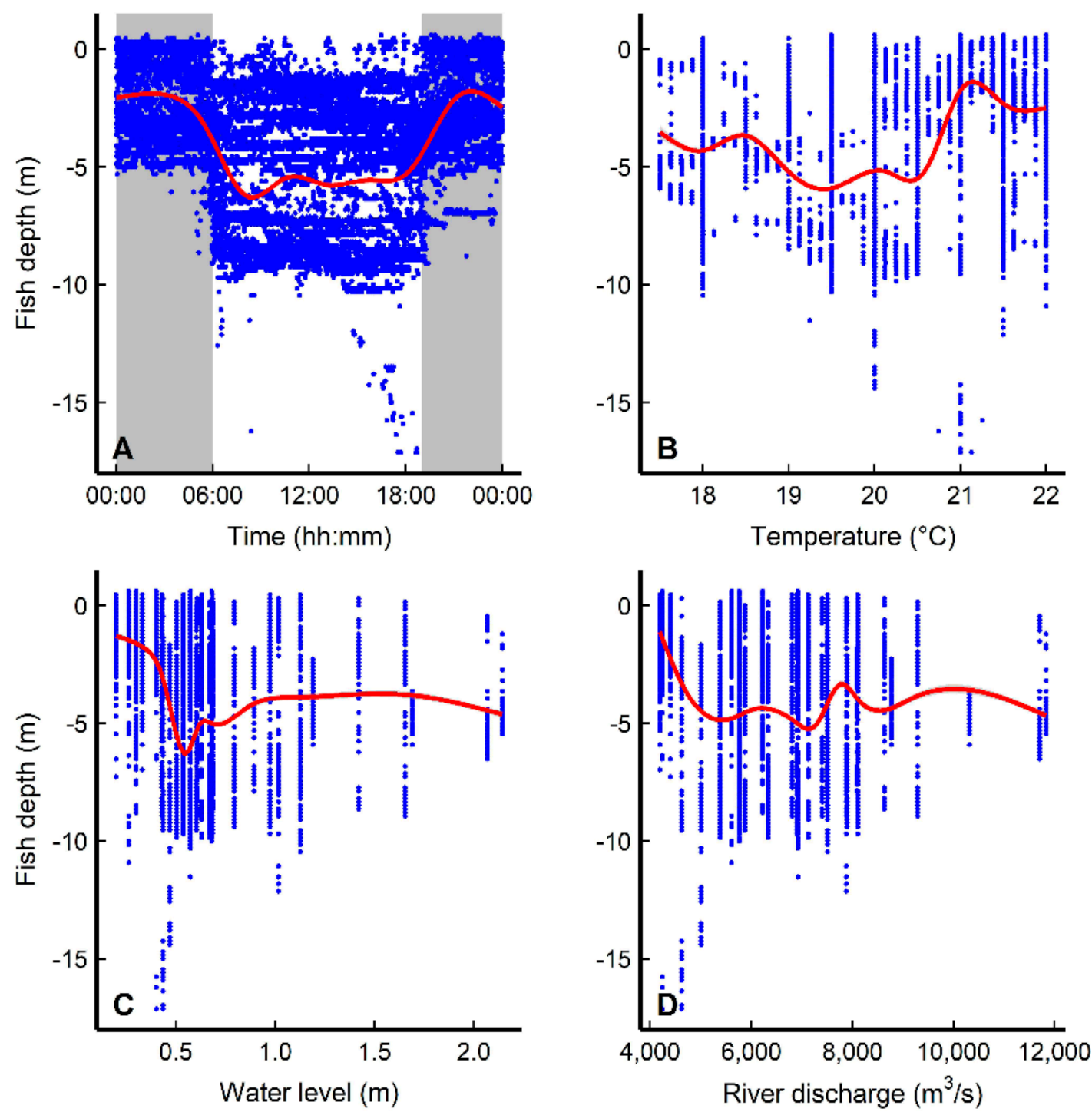

Figure 6. Effects of diel phase, temperature, water level, and river discharge on common carp depth. A smoothing (gam) curve with a span width of 0.5 was added for visual interpretation. 
Table 5. General additive mixed models for the effects of hour, water temperature, water level, and river discharge on the shortest distances to riverbanks (SDR) of common carp in the West River. An $f$ indicates a smooth function. The random effect of individual fish (ID) was included in all the models. $\mathrm{R}^{2}$ adj represents the adjusted proportion of the variance explained by the model, and LRT represents the likelihood ratio test statistic.

\begin{tabular}{|c|c|c|c|c|c|c|c|}
\hline Model & Explanatory Variables & Df & AIC & $\mathbf{R}^{2}$ adj & Model Compared & LRT & $p$ \\
\hline \multicolumn{8}{|l|}{ SDR } \\
\hline S1 & $\mathrm{f}($ hour $)+(1 \mid \mathrm{ID})$ & 5 & 32762 & 0.149 & \multirow{4}{*}{ S1 vs. S2 } & \multirow{4}{*}{377.7732} & \multirow{4}{*}{$<0.0001$} \\
\hline S2 & $f($ hour $)+f($ temperature $)+(1 \mid$ ID $)$ & 7 & 32388 & 0.00612 & & & \\
\hline S3 & \multirow{2}{*}{$\begin{array}{c}\mathrm{f}(\text { hour })+\mathrm{f}(\text { water level })+(1 \mid \mathrm{ID}) \\
\mathrm{f}(\text { hour })+\mathrm{f}(\text { river discharge })+ \\
(1 \mid \mathrm{ID})\end{array}$} & 7 & 32324 & 0.245 & & & \\
\hline S4 & & 7 & 32568 & 0.2 & & & \\
\hline \multicolumn{8}{|l|}{ Depth } \\
\hline D1 & $\mathrm{f}($ hour $)$ & 5 & 103728 & 0.296 & \multirow{4}{*}{ D1 vs. D2 } & \multirow{4}{*}{6676.919} & \multirow{4}{*}{$<0.0001$} \\
\hline $\mathrm{D} 2$ & $f($ hour $)+f($ temperature $)+(1 \mid \mathrm{ID})$ & 7 & 97055 & 0.489 & & & \\
\hline D3 & $\mathrm{f}($ hour $)+\mathrm{f}($ water level $)+(1 \mid$ ID $)$ & 7 & 96622 & 0.499 & & & \\
\hline D4 & $\begin{array}{c}\mathrm{f}(\text { hour })+\mathrm{f}(\text { river discharge })+ \\
(1 \mid \mathrm{ID})\end{array}$ & 7 & 99658 & 0.421 & & & \\
\hline
\end{tabular}
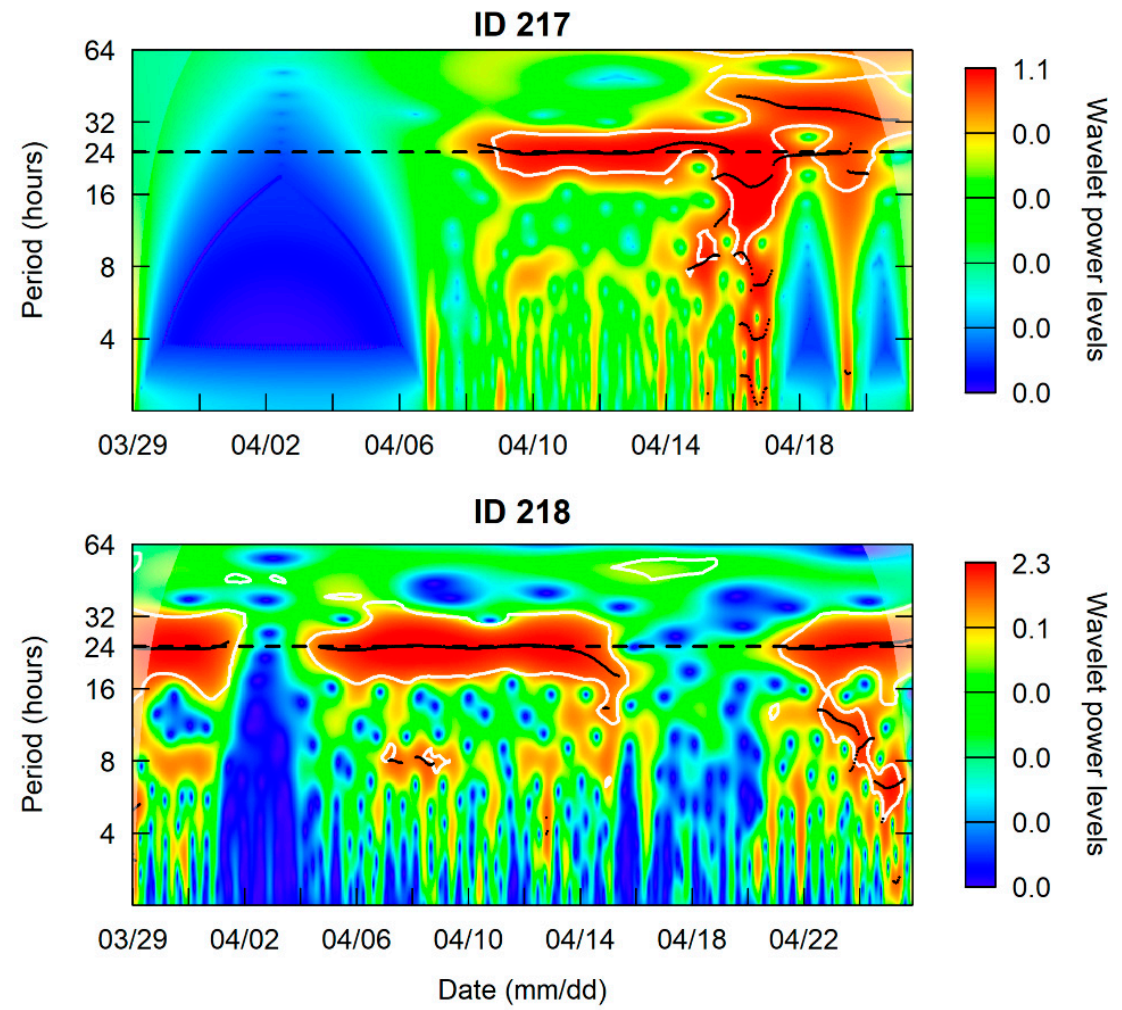

Figure 7. Wavelet spectra for depth data of common carp 217 and 218. Periodicities were detected in most of the tracking periods on a $24 \mathrm{~h}$ scale (horizontal dashed line). The thick contours delineated by white lines represent the $95 \%$ confidence level, and the scale bars represent the intensity of the time-frequency space over time.

\section{Discussion}

\subsection{Site Fidelity}

The common carp in this study were detected for an average of $39.38 \mathrm{~d}$, with an average TP of $42 \mathrm{~d}$ throughout the study period $(89 \mathrm{~d})$. These results indicate that the common carp had a moderate 
site fidelity to the study area in the Zhaoqing section of the West River. Six of the eight tagged common carp left the study area, which indicates that common carp tend to migrate on large scales. This finding was consistent with Koehn and Nicol [27], who suggested that there is approximately a $25.4 \%$ chance of common carp migrating $>1 \mathrm{~km}$ or even $120 \mathrm{~km}$ in a month.

\subsection{Diel Pattern of Common Carp Movement and Distribution}

The diel behavioral pattern of common carp, especially during the reproductive periods, has rarely been reported. In our study, the diel pattern of common carp movement was shown in the differences in the hourly detections, SDRs, and fish depth; however, there were no significant differences in moving speed. During the night, the common carp were detected more frequently and stayed in shallower water near the riverbanks, while during the day, the common carp exhibited the opposite pattern of being detected less and scattered in deep water columns near the river center. Benito et al. [28] found no diel cycle in our study periods from March to May but a different diel pattern in warm seasons (June to September), with fish shifting from the deep bottom during the night to shallow waters during the day, in a small reservoir on the Ebro River stem. The simulated aquaculture tank experiment conducted by Rahman and Meyer [29] suggested that common carp tend to swim and school during the night, but graze and scatter in water columns where their preys are present during the day. Our result that fish individuals stayed in riparian shallow water during the night, but scatter in deep water columns during the day, was consistent with Rahman and Meyer [29]. As common carp tend to move to floodplain or shallow water with abundant plants for spawning [30,31], their migration to riparian shallow water during the night was probably related to spawning activity. Moreover, nocturnal activity reduced the risk of getting caught by visually oriented predators [11], including human beings, for common carp adults, and their offspring.

Our study was the first to determine the diel rhythm and horizontal and vertical space use of common carp in the wild during its spawning season. These results have great implications for the population management in its native range and invaded areas, for instance, the results indicated that it would be an ideal choice to catch the common carp in the riparian areas at night during its breading seasons.

\subsection{Habitat Use}

Animal space use has been addressed of two complementary parts of geographic and environmental space [6]. Animal's movements or geographic space change is a response to changes in the environmental spaces to satisfy its requirements in terms of refuge or resources [6]. We found that common carp prefer habitats in riparian shallow water or around the sand bar, as suggested by the HSI, and migrate to riparian shallow water during the night from March to May, as revealed by the SDR and depth data. These results were in agreement with those of previous studies, e.g., common carp showed a significant preference for shallow, vegetated habitats during all seasons [32], migrated to floodplains, flooded grass flats, wetlands, and marshes to spawn [33,34], and aggregated in shallow water close to the shore during the spawning period in May and June [35]. Thus, riparian shallow waters with abundant macrophytes or inundated areas of terrestrial vegetation (e.g., marshes, wetlands and floodplains) [32] are the preferred habitat and spawning grounds of common carp.

Biologically, environmental space changes may have significant impact on the fish species' adaptability [36] and habitat availability [37]. To maximize its own adaptability, fish could change its habitat use patterns through movement. In this study, common carp habitat use, represented by its SDRs and depth, were influenced by the water temperature, water level, and river discharge (Table 5). For the common carp, the water temperature from March to April $\left(17.50{ }^{\circ} \mathrm{C}\right.$ to $\left.22.5^{\circ} \mathrm{C}\right)$ aligned with the required spawning water temperature $\left(16-22^{\circ} \mathrm{C}\right)$ and spawning periods from February to April in the West River, as suggested by Tan, et al. [19]. The lowest peak of the SDRs, at approximately $20^{\circ} \mathrm{C}$ (shown in Figure 5B), was probably related to spawning activity. 
The water level and river discharge were significantly correlated in our study, and their influences acted in combination. The river discharge in our study ranged from $4190 \mathrm{~m}^{3} / \mathrm{s}$ to $12,600 \mathrm{~m}^{3} / \mathrm{s}$; a rise in river discharge accelerates common carp gonadal development and spawning activities [19]. Under a river discharge of less than $8000 \mathrm{~m}^{3} / \mathrm{s}$, the common carp exhibited no apparent refuge behaviors, as shown by [28], but migrated to the deep water farther from the riverbanks when the river discharge increased. To some extent, when the river discharge exceeded $8000 \mathrm{~m}^{3} / \mathrm{s}$, the common carp tended to migrate to riparian habitats for refuge. This was in agreement with previous findings that high river discharges resulted in common carp moving to floodplains or shallow riparian habitats [28,30].

This study provided new information on fine-scale common carp movement and habitat use during the spawning season from April to June, which is essential for common carp population management, habitat restoration, and river ecosystem rehabilitation. Moreover, the nonsignificant attractiveness of AFNs for common carp indicates that more effort is required to optimize AFN management, material selection, and structural design. One important suggestion is to replace AFNs with newly made nests frequently, i.e., to use each nest for less than $24 \mathrm{~d}$, as Li, et al. [38] found that the number of common carp eggs was negatively correlated with the deployment periods and reached zero on the 24th day after deployment, probably because of the decay of the giant reed leaves over time.

Common carp are also one of the world's most destructive invasive species and have caused devastating effects on the aquatic ecosystems of several continents, for instance Africa, America and Oceania [17]. The population control and eradication have been the main targets in relevant research for several decades $[17,34,35]$. Our novel results on its movement pattern and habitat use, especially the diel habitat use pattern on horizontal and vertical axes, will have great application significance for common carp population control or even eradication in its invaded continents.

\section{Conclusions}

Our acoustic fine-scale tracking provides new information on common carp movement behaviors and habitat use. Common carp had a moderate site fidelity to the particular Zhaoqing section of the West River. We first found out an evident diel pattern on movement behaviors and habitat use of common carp in the wild during its breeding season, as revealed by the distinct differences in hourly detections, SDRs, and depth of tagged common carp individuals between day and night. These will have important implications for its population management in its native range and invaded areas. Its preferences for natural habitat rather than artificial habitats (e.g., AFNs) require more efforts to optimize the river habitat restoration approaches in the Pearl River. The significant environmental effects of the water temperature, water level, and river discharge on its habitat use suggested a consideration of environmental factors in common carp population management and river ecosystem rehabilitation in future. The novel results of common carp movement and habitat use pattern will prove to be useful in the population restoration in its native range and the population control/eradication in its invaded continents.

Supplementary Materials: The following are available online at http://www.mdpi.com/2073-4441/12/8/2233/s1, Figure S1: Artificial fish nests made by giant reed and bamboos in the studied West River, Figure S2: Acoustic detection range test shows the detection percentage along the distance from the test tag, Figure S3: The external acoustic tag attachment on common carp in our study, Figure S4: The water temperature, water level and river discharge in the study area at the downstream of the West River from March 21 to June 17 in 2017.

Author Contributions: Conceptualization, Y.Z., Y.L., L.Z. and X.L.; Methodology, Y.Z. and L.Z.; Investigation, Y.Z., Z.W., S.Z. and J.L.; Writing-Original Draft Preparation, Y.Z., L.Z., Y.L. and X.L.; Visualization, Y.Z. and L.Z.; Funding acquisition, Y.Z., Y.L., J.L. and X.L. All authors have read and agreed to the published version of the manuscript.

Funding: The study was funded by the National Key R\&D Program of China (2018YFD0900902), the Central Public-interest Scientific Institution Basal Research Fund, CAFS (2017HY-ZD0103), Guangzhou Municipal Science and Technology Project (201707010448), and the Pearl River Fisheries Resources Investigation \& Evaluation Group Project (2020TD10, 2020ZJTD-04). 
Acknowledgments: We thank Jiping Yang, Yaqiu Liu, Tianzhen Xu, Tianxu Kuang, Ce Li, and Sanji Liang for their great assistances during the receiver deployment and fish tags attachment. We also thank the two anonymous reviewers for their helpful suggestions.

Conflicts of Interest: The authors declare no conflict of interest. The sponsors had no role in the design, execution, interpretation, or writing of the study.

\section{References}

1. Block, B.A.; Dewar, H.; Blackwell, S.B.; Williams, T.D.; Prince, E.D.; Farwell, C.J.; Boustany, A.; Teo, S.L.H.; Seitz, A.; Walli, A.; et al. Migratory movements, depth preferences, and thermal biology of Atlantic bluefin tuna. Science 2001, 293, 1310-1314. [CrossRef] [PubMed]

2. Block, B.A.; Jonsen, I.D.; Jorgensen, S.J.; Winship, A.J.; Shaffer, S.A.; Bograd, S.J.; Hazen, E.L.; Foley, D.G.; Breed, G.A.; Harrison, A.L.; et al. Tracking apex marine predator movements in a dynamic ocean. Nature 2011, 475, 86-90. [CrossRef] [PubMed]

3. Heupel, M.R.; Knip, D.M.; de Lestang, P.; Allsop, Q.A.; Grace, B.S. Short-term movement of barramundi in a seasonally closed freshwater habitat. Aquat. Biol. 2011, 12, 147-155. [CrossRef]

4. Branco, P.; Amaral, S.D.; Ferreira, M.T.; Santos, J.M. Do small barriers affect the movement of freshwater fish by increasing residency? Sci. Total Environ. 2017, 581, 486-494. [CrossRef]

5. Boyce, M.S.; Johnson, C.J.; Merrill, E.H.; Nielsen, S.E.; Solberg, E.J.; van Moorter, B. Can habitat selection predict abundance? J. Anim. Ecol. 2016, 85, 11-20. [CrossRef] [PubMed]

6. van Moorter, B.; Rolandsen, C.M.; Basille, M.; Gaillard, J.M. Movement is the glue connecting home ranges and habitat selection. J. Anim. Ecol. 2016, 85, 21-31. [CrossRef]

7. King, A.J. Ontogenetic patterns of habitat use by fishes within the main channel of an Australian floodplain river. J. Fish Biol. 2004, 65, 1582-1603. [CrossRef]

8. Rosenberger, A.; Angermeier, P.L. Ontogenetic shifts in habitat use by the endangered Roanoke logperch (Percina rex). Freshw. Biol. 2003, 48, 1563-1577. [CrossRef]

9. Kattel, G.R.; Closs, G.P. Spatial and temporal variation in the fish community of a South Island, New Zealand coastal lake. N. Z. J. Mar. Freshw. Res. 2007, 41, 1-11. [CrossRef]

10. Pépino, M.; Rodríguez, M.A.; Magnan, P. Shifts in movement behavior of spawning fish under risk of predation by land-based consumers. Behav. Ecol. 2015, 26, 996-1004. [CrossRef]

11. Reebs, S.G. Plasticity of diel and circadian activity rhythms in fishes. Rev. Fish Biol. Fish. 2002, 12, 349-371. [CrossRef]

12. Winemiller, K.O.; Jepsen, D.B. Effects of seasonality and fish movement on tropical river food webs. J. Fish Biol. 1998, 53, 267-296. [CrossRef]

13. Meyer, C.G. Electronic tags reveal the hidden lives of fishes. Bull. Mar. Sci. 2017, 93, 301-318. [CrossRef]

14. Taylor, M.D.; van der Meulen, D.E.; Brodie, S.; Cadiou, G.; Knott, N.A. Applying acoustic telemetry to understand contaminant exposure and bioaccumulation patterns in mobile fishes. Sci. Total Environ. 2018, 625, 344-354. [CrossRef] [PubMed]

15. Kottelat, M.; Freyhof, J. Handbook of European Freshwater Fishes; Kottelat, Cornol, Switzerland and Freyhof, Berlin, Germany. 2007, p. 646. Available online: https://www.nhbs.com/handbook-of-european-freshwaterfishes-book (accessed on 10 February 2017).

16. Le, P. Fauna Sinica Actinopterygii Cypriniformes III; Science Press: Beijing, China, 2000. (In Chinese)

17. Stuart, I.G.; Conallin, A.J. Control of globally invasive common carp: An 11-year commercial trial of the Williams' cage. N. Am. J. Fish. Manag. 2018, 38, 1160-1169. [CrossRef]

18. Lu, K. The Fisheries Resource in the Pearl River; Guangdong Science and Technology Press: Guangzhou, China, 1990. (In Chinese)

19. Tan, X.; Li, X.; Lin, J.; Li, Y.; Bi, Y.; Li, J.; Wang, C. Early morphogenesis and laval resources of common carp at Zhaoqing section in the Pearl River. J. Dalian Fish. Univ. 2009, 24, 125-129. (In Chinese)

20. Freyhof, J.; Kottelat, M. Cyprinus Carpio, Wild Common Carp. In The IUCN Red List of Threatened Species 2008; IUCN: Gland, Switzerland, 2008.

21. Pan, P.; Li, Y.; Li, X. Effect evaluation of artificial fishnest on common carp (Cyprinus carpio) in Xijiang River. Freshw. Fish. 2016, 46, 45-49. (In Chinese) 
22. Brooks, M.E.; Kristensen, K.; van Benthem, K.J.; Magnusson, A.; Berg, C.W.; Nielsen, A.; Skaug, H.J.; Mächler, M.; Bolker, B.M. Modeling zero-inflated count data with glmmTMB. BioRxiv 2017, 132753. [CrossRef]

23. Lindén, A.; Mäntyniemi, S. Using the negative binomial distribution to model overdispersion in ecological count data. Ecology 2011, 92, 1414-1421. [CrossRef]

24. Aho, K.; Derryberry, D.; Peterson, T. Model selection for ecologists: The worldviews of AIC and BIC. Ecology 2014, 95, 631-636. [CrossRef]

25. Roesch, A.; Schmidbauer, H. WaveletComp 1.1: A guided Tour through the R Package. 2018. Available online: https://CRAN.R-project.org/package=WaveletComp (accessed on 1 June 2019).

26. Booth, G.D.; Niccolucci, M.J.; Schuster, E.G. Identifying Proxy Sets in Multiple Linear Regression [Microform]: An Aid to Better Coefficient Interpretation; U.S. Dept. of Agriculture, Forest Service, Intermountain Research Station: Ogden, UT, USA, 1993.

27. Koehn, J.D.; Nicol, S.J. Comparative movements of four large fish species in a lowland river. J. Fish Biol. 2016, 88, 1350-1368. [CrossRef] [PubMed]

28. Benito, J.; Benejam, L.; Zamora, L.; Garcia-Berthou, E. Diel cycle and effects of water flow on activity and use of depth by Common Carp. Trans. Am. Fish. Soc. 2015, 144, 491-501. [CrossRef]

29. Rahman, M.M.; Meyer, C.G. Effects of food type on diel behaviours of common carp Cyprinus carpio in simulated aquaculture pond conditions. J. Fish Biol. 2009, 74, 2269-2278. [CrossRef] [PubMed]

30. Jones, M.J.; Stuart, I.G. Lateral movement of common carp (Cyprinus carpio L.) in a large lowland river and floodplain. Ecol. Freshw. Fish 2009, 18, 72-82. [CrossRef]

31. Conallin, A.J.; Smith, B.B.; Thwaites, L.A.; Walker, K.F.; Gillanders, B.M. Exploiting the innate behaviour of common carp, Cyprinus carpio, to limit invasion and spawning in wetlands of the River Murray, Australia. Fish. Manag. Ecol. 2016, 23, 431-449. [CrossRef]

32. Penne, C.R.; Pierce, C.L. Seasonal distribution, aggregation, and habitat selection of common carp in Clear Lake, Iowa. Trans. Am. Fish. Soc. 2008, 137, 1050-1062. [CrossRef]

33. Chizinski, C.J.; Bajer, P.G.; Headrick, M.E.; Sorensen, P.W. Different migratory strategies of invasive Common Carp and native northern pike in the American Midwest suggest an opportunity for selective management strategies. N. Am. J. Fish. Manag. 2016, 36, 769-779. [CrossRef]

34. Taylor, A.H.; Tracey, S.R.; Hartmann, K.; Patil, J.G. Exploiting seasonal habitat use of the common carp, Cyprinus carpio, in a lacustrine system for management and eradication. Mar. Freshw. Res. 2012, 63, 587-597. [CrossRef]

35. Hennen, M.J.; Brown, M.L. Movement and spatial distribution of Common Carp in a South Dakota Glacial Lake System: Implications for management and removal. N. Am. J. Fish. Manag. 2014, 34, 1270-1281. [CrossRef]

36. Wang, J.Y.; Kuo, T.C.; Hsieh, C.H. Causal effects of population dynamics and environmental changes on spatial variability of marine fishes. Nat. Commun. 2020, 11, 2635. [CrossRef]

37. Parsapour-Moghaddam, P.; Brennan, C.P.; Rennie, C.D.; Elvidge, C.K.; Cooke, S.J. Impacts of channel morphodynamics on fish habitat utilization. Environ. Manag. 2019, 64, 272-286. [CrossRef] [PubMed]

38. Li, Y.; Chen, W.; Xia, Y.; Yang, J.; Zhu, S.; Li, X. Selection of artificial fish nest material and influencing factors of implementation effects. South China Fish. Sci. 2020, 16, 21-28. (In Chinese) [CrossRef]

(C) 2020 by the authors. Licensee MDPI, Basel, Switzerland. This article is an open access article distributed under the terms and conditions of the Creative Commons Attribution (CC BY) license (http://creativecommons.org/licenses/by/4.0/). 